\title{
Multidisciplinary dental treatment for Papillon-Lefèvre syndrome: case report
}

\author{
Tratamento odontológico multidisciplinar da Sindrome \\ de Papillon-Lefèvre: Relato de caso
}

\author{
Paolla Leão MARTINS1 iD https://orcid.org/0000-0002-5146-1785 \\ Francine do Couto Lima MOREIRA² iD https://orcid.org/0000-0002-4950-1864 \\ Cerise de Castro CAMPOS ${ }^{2}$ iD https://orcid.org/0000-0003-2156-3315 \\ Virgílio Moreira RORIZ3 iD https://orcid.org/0000-0003-2028-164X
}

\begin{abstract}
Papillon-Lefèvre syndrome is a rare autosomal recessive genetic disorder with a prevalence of one to four cases per million. It is characterized by diffuse or localized palmoplantar hyperkeratosis. It has no gender or racial predilection. Etiology and pathogenesis of Papillon-Lefèvre syndrome are still obscure. However, Papillon-Lefèvre syndrome is believed to be caused by a genetic defect located on chromosome 11, which is responsible for coding cathepsin C, a lysosomal protease present mainly in the epithelial regions such as the palms, soles of feet, knees, and keratinized oral mucosa, which are the most commonly affected areas in Papillon-Lefèvre syndrome. Periodontitis is an oral manifestation of Papillon-Lefèvre syndrome that results in early loss of deciduous and permanent teeth. This report aims to describe a case of an 11-year-old male patient diagnosed with Papillon-Lefèvre syndrome at 4 years of age. After the diagnosis, the child lost all deciduous teeth and sought dental service at the Federal University of Goiás 2 years ago. He is being treated using a multidisciplinary approach involving the areas of periodontics, pathology, and orthodontics to avoid loss of permanent teeth and to provide conditions for preserving the health of remaining teeth while maintaining the function and the esthetics.
\end{abstract}

Indexing terms: Papillon-Lefevre disease. Periodontal disease. Tooth loss.

\section{RESUMO}

A síndrome de Papillon-Lefèvre é um distúrbio genético autossômico recessivo raro, com prevalência de um a quatro casos por milhão. É caracterizada por hiperqueratose palmoplantar difusa ou localizada. Não tem predileção por gênero ou raça. Etiologia e patogênese da síndrome de Papillon-Lefèvre ainda são obscuras. No entanto, acredita-se que a síndrome de Papillon-Lefèvre seja causada por um defeito genético localizado no cromossomo 11, responsável pela codificação da catepsina $C$, uma protease lisossômica presente principalmente nas regiões epiteliais, como palma das mãos, solas dos pés, joelhos e mucosa oral queratinizada, que são as áreas mais afetadas pela síndrome de Papillon-Lefèvre. Periodontite é uma manifestação oral da SPL que resulta em perda precoce de dentes

\footnotetext{
$\boldsymbol{V} \mathbf{V}$

1 Universidade Federal de Goiás, Faculdade de Odontologia. Goiânia, GO, Brasil.

2 Universidade Federal de Goiás, Faculdade de Odontologia, Departamento de Prevenção e Reabilitação Oral. Goiânia, GO, Brasil.

3 Universidade Federal de Goiás, Faculdade de Odontologia, Departamento de Ciências Estomatológicas. Av. Universitária, s/n., Setor Leste Universitário, 74605-020, Goiânia, GO, Brasil. Correspondence to: VM Roriz. E-mail: <vmroriz@hotmail.com>.

$\boldsymbol{\nabla} \boldsymbol{\nabla} \boldsymbol{\nabla}$

How to cite this article

Martins PL, Moreira FCL, Campos CC, Roriz VM, Multidisciplinary dental treatment for Papillon-Lefèvre syndrome: case report. RGO, Rev Gaúch Odontol. 2020;68: e20200042. http://dx.doi.org/10.1590/1981-86372020000423635
} 
decíduos e permanentes. Este artigo tem como objetivo descrever um caso de um paciente de 11 anos de idade com diagnóstico de síndrome de Papillon-Lefèvre aos 4 anos. Após o diagnóstico, a criança perdeu todos os dentes decíduos e procurou atendimento odontológico na Universidade Federal de Goiás, há cerca de 2 anos. Ele está sendo tratado usando uma abordagem multidisciplinar envolvendo as áreas de periodontia, patologia e ortodontia para evitar a perda de dentes permanentes e fornecer condições para preservar a saúde dos dentes restantes, mantendo a função e a estética.

Termos de indexação: Doença de Papillon-Lefèvre. Doenças periodontais. Perda de dente.

\section{INTRODUCTION}

Papillon-Lefèvre syndrome (PLS) was first described in 1924 by two French doctors. It is an autosomal recessive disorder with a prevalence of one to four cases per million [1]. Clinically, PLS is characterized by diffuse palmoplantar hyperkeratosis. Occasionally it may extend to the back of the hands, feet, knees, and elbows. It is associated with the presence of periodontitis that affects both primary and permanent teeth [2]. Both the genders are equally affected and there is no racial predilection. However, previous literature reports a possible genetic predisposition to the disease, since consanguinity was observed in one third of the patients with PLS [3]. Associated features may include predisposition to bacterial diseases (especially liver abscess), mental retardation, and intracranial calcifications $[4,5]$.

The onset of periodontal disease coincides with the eruption of the first deciduous teeth. The appearance of skin lesions can also coincide with this period, since skin lesions occur predominantly between 6 months and 4 years of age [6]. In these cases, periodontal disease is aggressive and does not respond positively to traditional periodontal treatment. Primary teeth are generally lost around 4 years of age and permanent teeth at around 14 years of age [7]. Hypermobility, migration, and exfoliation of teeth can be observed without any sign of root resorption. Gingiva becomes inflamed with the eruption of the first deciduous teeth and there is a rapid resorption of the alveolar bone. As soon as the child becomes edentulous, gingiva returns to normal, leaving no signs of periodontal disease, which reappears with the eruption of the first permanent teeth and all or most of the teeth are lost during adolescence [8]. Radiographic features include generalized loss of alveolar bone with "floating teeth" appearance [9].

The genetic defect identified in the syndrome was mapped to chromosome 11q14-q21. It involves a mutation in the gene that encodes the activity of cathepsin $C$, a lysosomal protease present mainly in epithelial regions such as the palms, soles of feet, knees, and keratinized oral gingiva. These areas are the most commonly affected ones in PLS [10]. Cathepsin C is also present in the cells of the immune system such as polymorphonuclear leukocytes and macrophages. These cells are altered in PLS. Decreased neutrophil phagocytosis, decreased leukocyte chemotaxis, and decreased number of peripheral $\mathrm{T} 2$ lymphocytes are considered the probable causes of increased susceptibility to infections. Non-functional cathepsin C can reduce the host's response against pathogens involved in periodontal disease [3].

The vast majority of literature about PLS shows agreement regarding generalized dental loss, which results in edentulism as an inevitable outcome and regarding the failure of conventional periodontal treatment. The treatment of choice for periodontal disease in PLS is a combination of scaling and root planing (SRP) and antibiotic therapy. Some studies suggest that extraction of all teeth followed by a period of edentulism can play an important role in control of periodontal disease, minimizing infection in permanent teeth [7,11-15].

Microbiological findings have shown that Actinobacillus actinomycetemcomitans (AA), Capnocytophaga sp, Porphyromonas gingivalis, Fusobacterium nucleatum, Prevotella intermedia, Treponema denticola, and Rhizopus oryzae are among the microorganisms involved in periodontal disease as well as in cutaneous lesions in PLS. AA is most commonly found in dental biofilm and its eradication appears to play an important role in the success of periodontal treatment [10].

The objective of this case report was to present a clinical case of an 11-year-old patient diagnosed with PLS who was treated with a multidisciplinary approach at School of Dentistry of Federal University of Goias, Brazil.

\section{CASE REPORT}

An 11-year-old male patient reported to School of Dentistry of Federal University of Goias in December 2016. He was accompanied by his mother and was diagnosed with PLS by another doctor. He was under treatment for 
PLS and was referred for periodontal evaluation. On clinical examination, palmoplantar hyperkeratosis (figure $1 \mathrm{~A}$ and 1B) and periodontitis with fast bone loss associated with PLS was observed. According to the history provided by the mother, the patient did not present any cognitive problems. He had frequent episodes of furunculosis and used daily Acitretin to treat the hyperkeratotic lesions. In the history of the current illness, it was reported that the child had early exfoliation of some teeth in the first years of life.

During the anamnesis, consanguinity was found between the parents, who were cousins. There were other cases of consanguinity in the family, but no other case of PLS.

Intraoral examination showed advanced generalized bone loss (figure 2). Especially, bone loss could be observed in the region of first permanent maxillary molars and incisors on panoramic radiography (figure 3 ) and extensive probing depths were recorded on specialized periodontal examination.

The patient had an abnormal tissue growth on the vestibular face of the tooth 16 . On biopsy, it was diagnosed as inflammatory fibrous hyperplasia. Periodontal treatment including SRP was performed for all teeth in combination with antibiotic therapy (500 mg amoxicillin + $400 \mathrm{mg}$ metronidazole for 10 days).
Subsequently, the patient was referred for orthodontic evaluation (figure 4). In orthodontic evaluation, maxillary atresia and occlusal problems were observed. The associated periodontal disease had led to increased bone loss and greater tooth mobility. The orthodontic diagnosis included Angle's class III malocclusion, left subdivision, tooth 22 in anterior crossbite, bilateral posterior crossbite, space loss in the maxilla with impaction of the teeth 15 and 25 , generalized diastemas, and loss of space in the lower arch. Thus, concomitant periodic periodontal treatment and orthodontic intervention was performed to improve the occlusion

The patient was instructed to report for monthly follow-up of the orthodontic device. However, he failed to report for the follow-up. He returned 2 months after installation of the device. On examination, poor oral hygiene, correction of the crossbite with the tooth 22, and maxillary expansion was observed (figure 5). It was decided to remove the device due to non-compliance of the patient regarding plaque control (figure 6).

Currently, the patient reports regularly for periodontal follow-up. His mother signed the free and informed consent authorizing the treatment, registration, and publication of this case report.
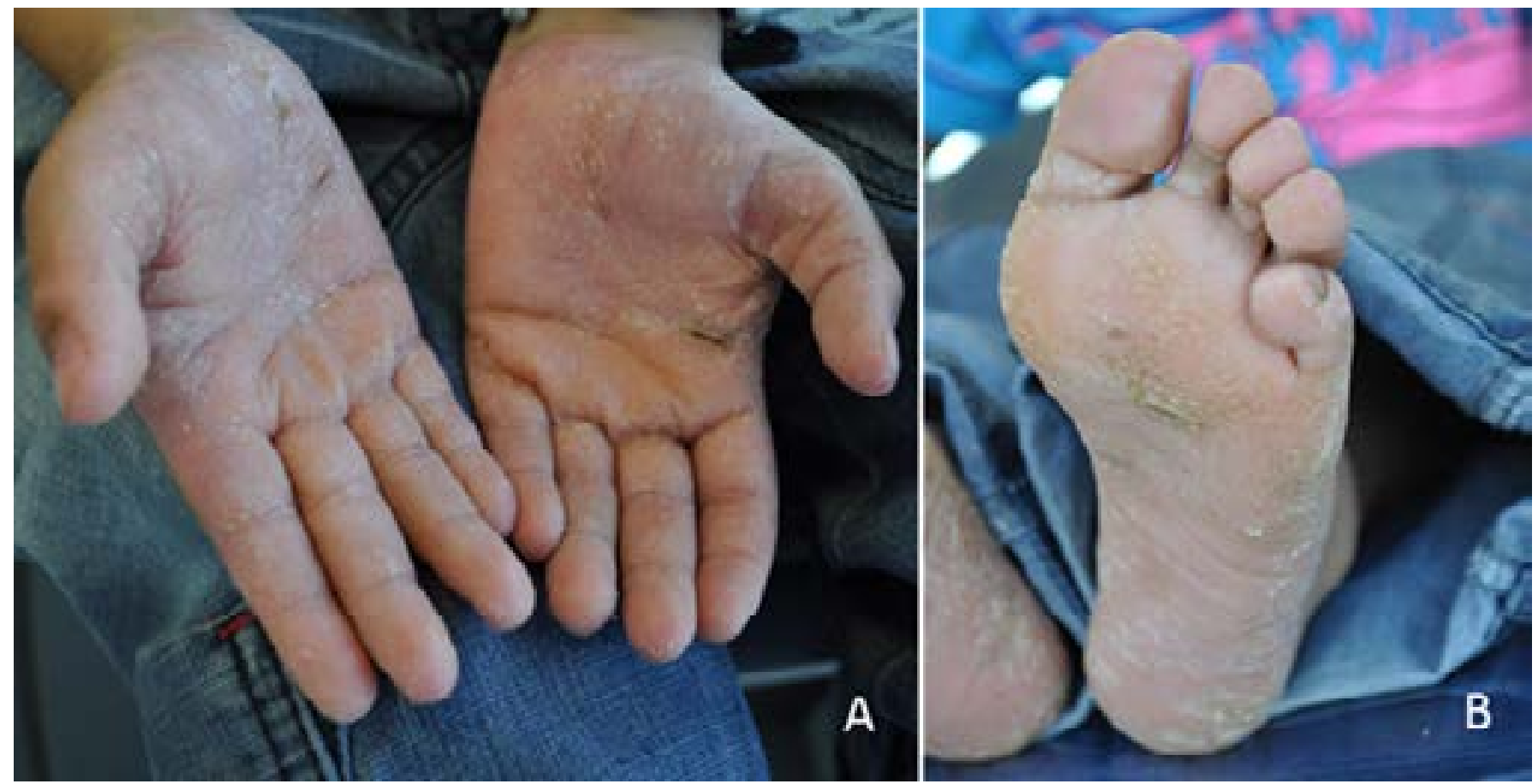

Figure 1. A) Hyperkeratosis of the palms and B) hyperkeratosis of the soles of the feet characteristic of Papillon-Lefèvre Syndrome. 


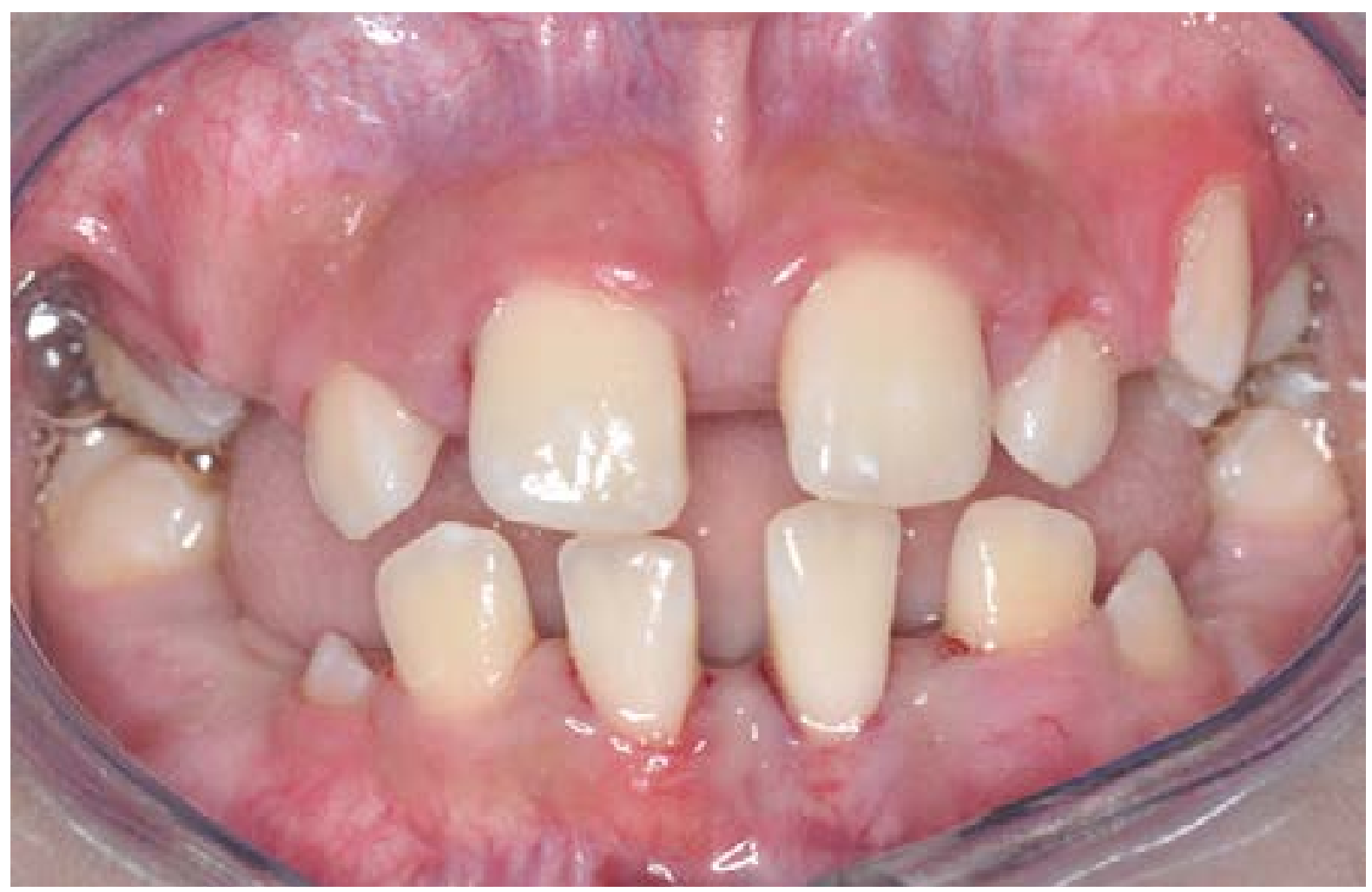

Figure 2. Initial intraoral photograph (frontal view)

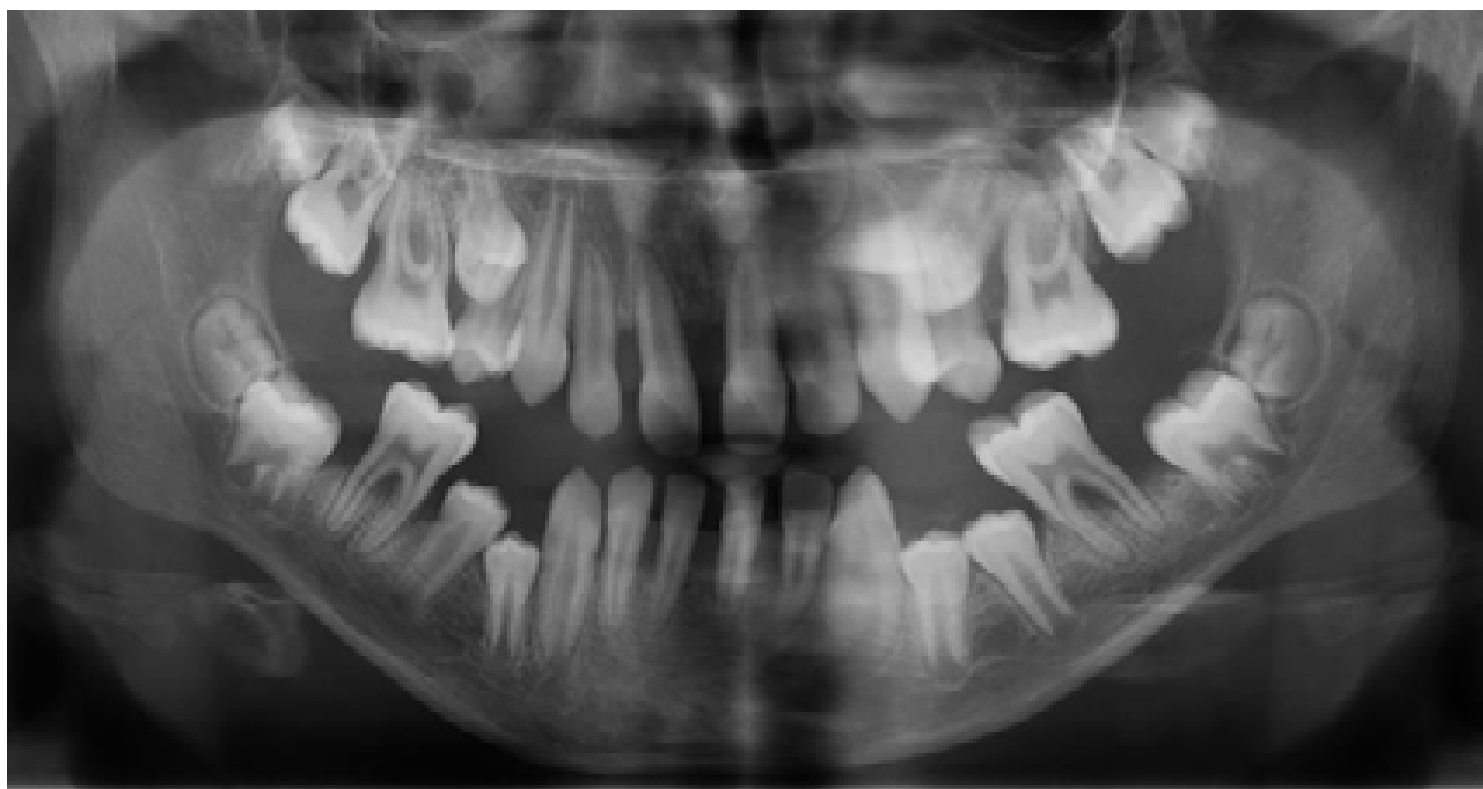

Figure 3. Initial panoramic radiograph showing generalized bone loss. Bone loss can be seen especially in the region of maxillary permanent first molars and incisors 


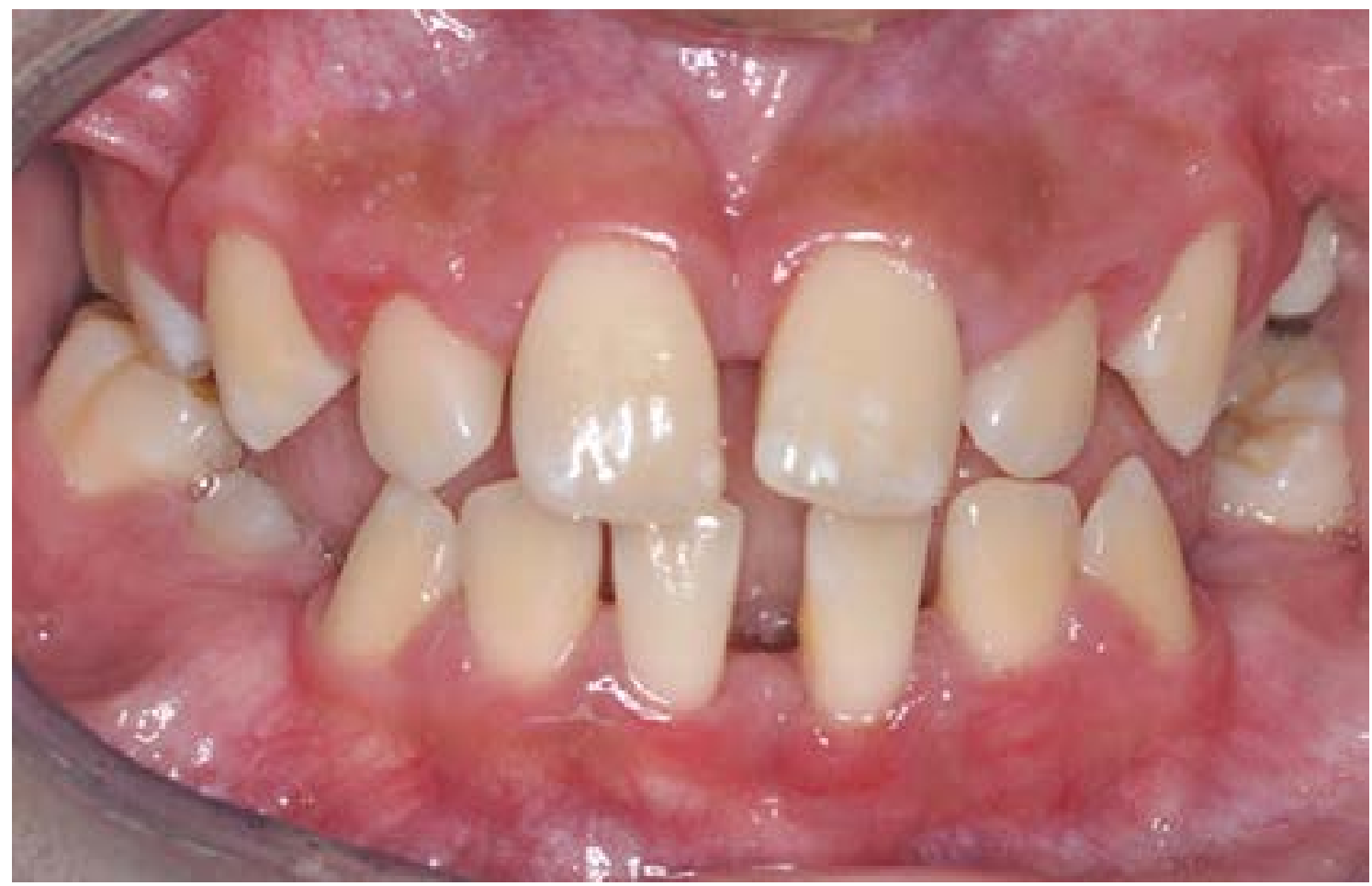

Figure 4. Patient was referred for orthodontic treatment to improve the occlusion and to correct anterior crossbite with the tooth 22.

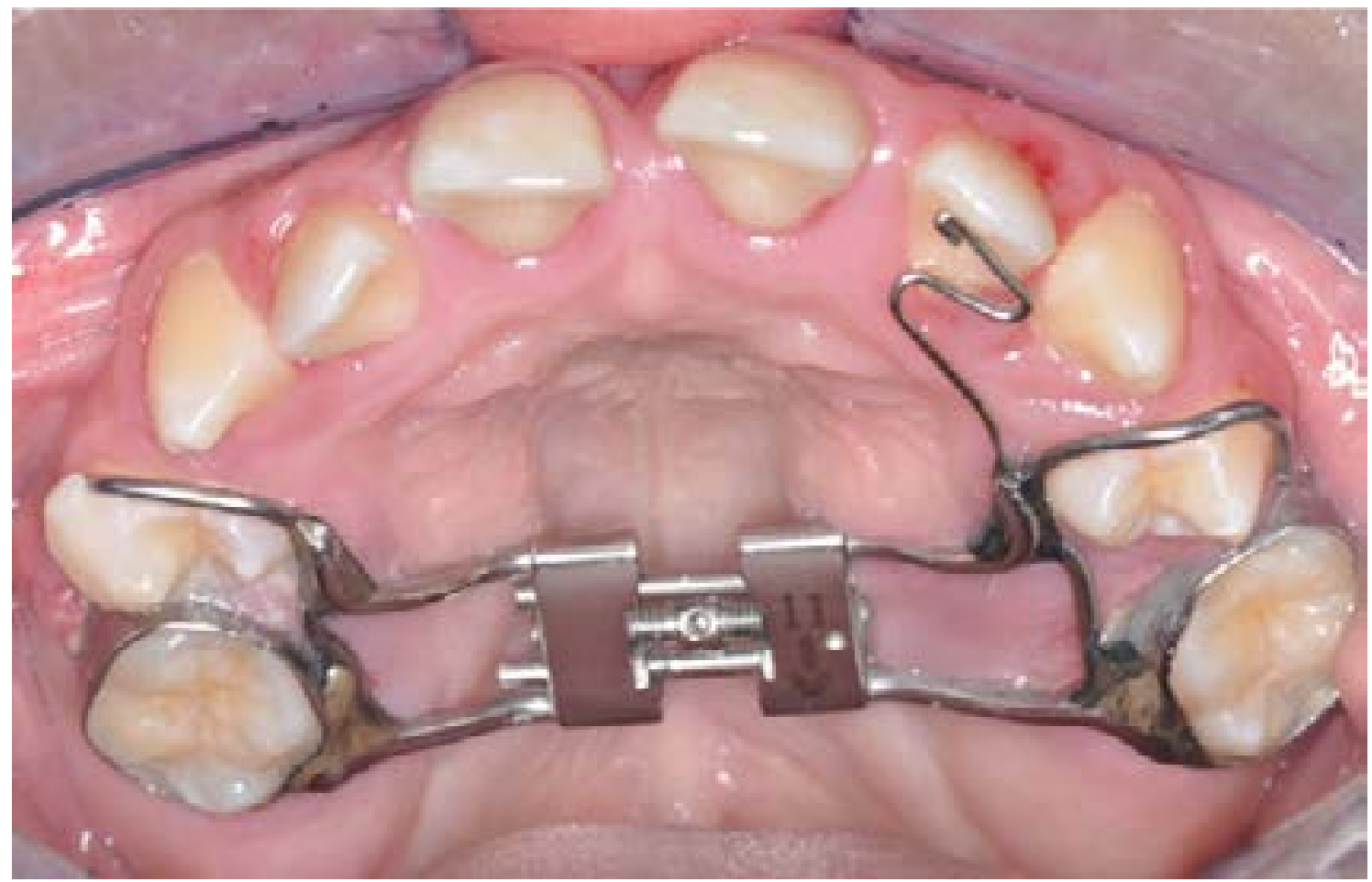

Figure 5. Occlusal view of Hyrax disjunction appliance with digital spring for improving the occlusion and for correcting the anterior crossbite with the tooth 22. 


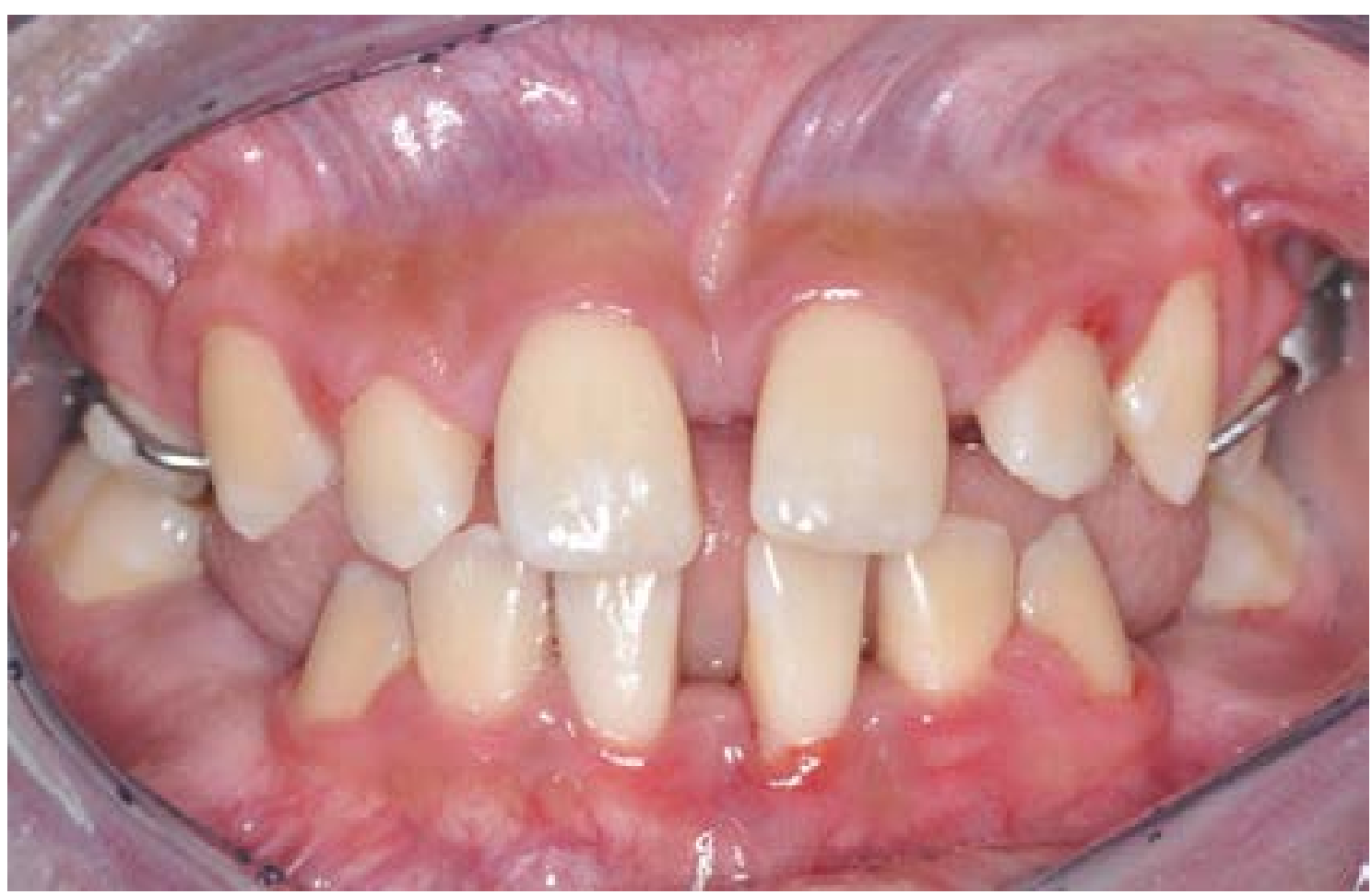

Figure 6. Frontal view after 2 months and 10 days of using the Hyrax disjunction appliance with digital spring.

\section{DISCUSSION}

There are some protocols with variable success rates for periodontal treatment of patients with PLS [2,6$9,11-15]$. Usually, individuals affected by PLS show total loss of permanent dentition while they are still in the adolescent phase [8]. In an attempt to avoid this outcome and due to the fact that patients arrive at different ages and conditions for professionals, several protocols with different strategies and doses of antibiotics are proposed, all of which have varying success rates. However, in the vast majority of cases, it is noticed that Aa has been reported to play an important role in PLS-associated periodontitis and its elimination is a major factor for the success of the treatment [7].

In the present case report, the patient exhibited classic characteristics of PLS sufficient for the clinical diagnosis of the syndrome. These included palmoplantar hyperkeratosis and severe periodontitis leading to early loss of primary teeth. The process of early loss of permanent teeth had already begun [2]. Consanguinity was also observed between the parents [3].

The majority of previous cases reports regarding PLS agree about the failure of conventional periodontal treatment and about the generalized tooth loss resulting in edentulism, which is an almost inevitable prognosis for patients with PLS [2,3,6-9].

There is a consensus in the literature regarding the essential need for patient compliance regarding plaque control, the importance of traditional periodontal treatment with SRP, the indispensability of extraction of compromised primary teeth, and the need for a period of edentulism to avoid the infection from reaching the permanent toothgerms. However, different protocols of treatment can be found regarding antibiotic therapy [11-15]. De Vree et al. [16] administered $250 \mathrm{mg}$ metronidazole every 6 hours for 5 days in the primary dentition and $375 \mathrm{mg}$ amoxicillin and 250 mg metronidazole every 8 hours for one week after the eruption of permanent teeth [15]. Out of the two patients treated with this regimen, one patient showed a satisfactory result, while the other lost all teeth. Lundgren and Renvert [13] performed a study involving 15 patients with PLS who underwent initial treatment using these same medications, but with different dosages and times of administration [12]. They used $250 \mathrm{mg}$ amoxicillin twice a day and $250 \mathrm{mg}$ metronidazole three times a day for 6 weeks followed by $250 \mathrm{mg}$ tetracycline once a day for 1.5 years. Only four of the treated patients showed satisfactory results [12]. Lux et 
al. [15] used $250 \mathrm{mg}$ amoxicillin every 8 hours and $250 \mathrm{mg}$ metronidazole every 12 hours for one week and achieved a satisfactory result in the treated patient [14]. Ullbro et al. [12] performed a study involving 35 patients with PLS who were treated with $20-50 \mathrm{mg}$ amoxicillin/ $\mathrm{kg} /$ day or $20-40$ mg amoxicillin with potassium clavulanate/ $\mathrm{kg} / \mathrm{day}$ for 2 weeks and reported an average of 3.5 missing teeth in patients who complied with the treatment [11]. Toygar et al. [14] reported a case with 13 years of successful followup of the treatment regimen involving $100 \mathrm{mg}$ tetracycline once a day for three weeks [13]. These medications were the most commonly reported ones in published works. In the present report, it was administered 500 mg amoxicillin and $400 \mathrm{mg}$ metronidazole three times a day for 10 days. However, no satisfactory results were observed, possibly due to the patient's non-compliance in maintaining plaque control.

The success of periodontal treatment depends on the conversion of active periodontitis to an inactive state [16]. In the present case, although the patient did not have well-controlled periodontal disease, we opted for orthodontic treatment, since the malocclusion (anterior and posterior crossbites) was worsening his periodontal condition. The orthodontic treatment was aimed at improving teeth alignment and modifying areas with excessive occlusal trauma to favor occlusion and to facilitate better outcome of periodontal treatment. The patient showed lack of compliance and motivation for maintaining oral hygiene in addition to poor adherence to control schedules for continued treatment. Hence, it was necessary to remove the orthodontic device before the planned date, as the accumulation of plaque associated with bone loss and orthodontic movement could contribute to increased bone resorption. Other authors have reported the use of orthodontic appliances in patients with PLS. Lux et al. (2005) subjected a patient with PLS to orthodontic treatment. After obtaining success with conventional periodontal treatment combined with antibiotic therapy and patient compliance for plaque control, periodontal disease was stable and orthodontic treatment was started. The desired space was achieved in the upper arch for the eruption of the impacted permanent teeth. However, in the mandible, the patient ended up losing the central incisors due to severe bone loss. At the end of the treatment, the authors reported having achieved success with orthodontic treatment [14]. Toygar et al. [14] also used orthodontics to obtain better esthetic and functional results in a patient who had malocclusion because of bad positioning of the teeth in the arch due to early tooth loss. Fixed orthodontic appliance was used to correct gyroversions and diastemas and the treatment was concluded with dental implants [13].

Specialties such as orthodontics and prosthodontics are important for providing children a better and functional dentition during the growth period. For edentulism, complete denture that needs to be replaced in short time intervals due to skeletal growth is a possible option. However, it is not acceptable for most of the patients. In this context, an intense and continuous periodontal and antibiotic therapy along with patient motivation seemed to be the best option for the possibility of preservation of periodontal health and maintaining as many teeth as possible, since the definitive treatment such as rehabilitation with implants is possible only after 18 years of age when the mandibular and maxillary growth has been stabilized [12].

Given the difficulty in preserving the teeth throughout life in individuals with PLS and due to the non-compliance of the patient in the present report, the treatment performed by us was palliative. The treatment was aimed at maintenance of permanent teeth for as long as possible and avoiding successive changes of prostheses after each tooth loss. Thus, the patient can choose the best definitive treatment according to his preference and/ or financial condition when he reaches adulthood.

It is essential that the diagnosis of PLS is made as early as possible so that the most efficient treatment can be instituted. Thus, dentists should be familiar with the syndrome and should be able to diagnose this rare condition and to choose the correct treatment for it. Early diagnosis can prevent or delay tooth loss, which can help preserve function and esthetics. A multidisciplinary treatment approach involving dermatologists, pediatricians, dentists, and psychologists is necessary for normal growth and development of patients with PLS.

\section{CONCLUSION}

In conclusion, with concomitant periodontal and orthodontic treatments, considerable reductions were observed in the probing depths and teeth mobility. The patient is being treated to avoid loss of permanent teeth and to provide conditions for preserving the health of remaining teeth while maintaining the function and the esthetics. 


\section{Collaborators}

PL MARTINS, conducting periodontal treatment of the patient. FCL MOREIRA, assistance in carrying out treatments and photographic documentation. CC CAMPOS, guidance on patient management and collaboration in writing the text. VM RORIZ, supervision of periodontal treatment, monitoring of the case and final writing of the text.

\section{REFERENCES}

1. Gorlin RJ, Sedano H, Anderson VE. The syndrome of palmarplantar hyperkeratosis and premature periodontal destruction of the teeth. J Pediatr. 1964; 65:895-908. http://dx.doi. org/10.1016/S0022-3476(64)80014-7

2. Sreeramulu B, Shyam N, Ajay P, Suman P. Papillon-Lefèvre syndrome: clinical presentation and management options. Clin Cosmet Investig Dent. 2015;7:75-81. http://dx.doi.org/10. 2147/CCIDE.S76080

3. AlBarrak ZM, Adel AS, Elna PC, Sukumaran A. Papillon-Lefèvre syndrome: a series of five cases among siblings. J Med Case Rep. 2016;10(1):260. http://dx.doi.org/10.1186/s13256-016-1 051-z

4. Zhang $Y$, Lundgren $T$, Renvert $S$, Tatakis DN, Firatli E, Uygur C, Hart PS, Gorry MC, Marks JJ, Hart TC. Evidence of a founder effect for four cathepsin $C$ gene mutations in Papillon-Lefèvre syndrome patients. J Med Genet. 2001;38(2):96-101. http:// dx.doi.org/10.1136\%2Fjmg.38.2.96

5. Kanthimathinathan HK, Browne F, Ramirez R, McKaig S, Debelle G, Martin J, et al. Multiple cerebral abscesses in Papillon-Lefèvre syndrome. Childs Nerv Syst. 2013;29(8):1227-9. http://dx.doi.org/10.1007/s00381-013-2152-2

6. Morgan RD, Hannon E, Lakhoo K. Renal abscess in PapillionLefèvre syndrome. Pediatr Surg Int. 2011;27(12):1381-3. http://dx.doi.org/10.1007/s00383-011-2931-3

7. Ullbro C, Crossner CG, Nederfors T, Alfadley A, ThestrupPedersen K.Dermatologic and oral findings in a cohort of 47 patients with Papillon-Lefèvre syndrome. J Am Acad Dermatol. 2003;48(3):345-51. http://dx.doi.org/10.1067/mjd.2003.197
8. Hart TC, Hart PS, Bowden DW, Michalec MD, Callison SA, Walker SJ, et al. Mutations of the cathepsin $C$ gene are responsible for Papillon-Lefevre syndrome. J Med Genet. 1999;36:881-7. http://dx.doi.org/10.1136/jmg.36.12.881

9. Dhanrajani PJ. Papillon-Lèfevre syndrome: clinical presentation and a brief review. Oral Surg Oral Med Oral Pathol Oral Radiol Endod. 2009;108(1):e1-7. http://dx.doi.org/10.1016/j. tripleo.2009.03.016

10. Idon PI, Olasoji HO, Fusami MA. Papillon-Lefevre Syndrome: Review of Literature and Report of Three Cases in the Same Family. Niger Post Med J. 2015;22(1):75-82. http://dx.doi.org/10.1186/s13256-016-1051-z

11. Ullbro C, Brown A, Twetman S. Preventive Periodontal Regimen in Papillon-Lefèvre Syndrome. Pediatr Dent. 2005;27:226-232. http://dx.doi.org/10.2147/CCIDE.S76080

12. Lundgren T, Renvert S. Periodontal treatment of patients with Papillon-Lefevre syndrome: a 3-year follow-up. J Clin Periodontol. 2004;31(11):933-938. http://dx.doi.org/10.11 11/j.1600-051X.2004.00591.x

13. Toygar HU, Kircelli U, Guzeldemir E. Combined therapy in a patient with papillon-lefevre syndrome: a 13-year follow-up. J Periodontol. 2007;9(78):1819-24. http://dx.doi.org/10.1 902/ jop.2007.070004

14. Lux CJ, Kugel B, Komposch G, Pohl S, Eickholz P. Orthodontic treatment in a patient with papillon-lefèvre syndrome. J Periodontol. 2005;4(76):642-50. http://dx.doi.org/10.1902/ jop.2005.76.4.642.

15. De Vree H, Steenackers K, De Boever JA. Periodontal treatment of rapid progressive periodontitis in 2 siblings with PapillonLefevre syndrome: 15-year follow-up. J Clin Periodontol. 2000;27(5):354-60. http://dx.doi.org/10.4103\%2F0972-124X. 115643

16. Calheiros A, Fernandes A, Quintão CA, Souza EV. Orthodontic movement in teeth with periodontal disease: a clinical case report. Rev Dent Press Ortodon Ortop Facial. 2005;10(2):111-18. http://dx.doi.org/10.1590/S1415-54192005000200014.

Received on: 11/8/2018 Final version resubmitted on: 17/2/2020 Approved on: 13/3/2020 